\title{
Reply to Mealey and Young
}

\author{
L. L. Betzig
}

Museum of Zoology, University of Michigan, Ann Arbor

The first of Mealey and Young's points was acknowledged in the paper on which they've commented. That the sample used was small is obvious: the analysis was intended to be "preliminary." As pointed out, "The sample is, like the HRAF and Ethnographic Atlas . . . and subsets of them . . . a a judgmental one . . . and a very small one as well. Inferences, therefore, should not at this point be extended beyond the societies described" (Betzig 1982; p. 210). Neither a Pearson Product Moment correlation statistic, nor any other statistic, has much meaning given such a disclaimer, other than to prompt or put off a further investigation of the problem. These results have since been retested on a larger sample (Betzig 1983, in press). A reanalysis of the relationships among hierarchy, despotism, and polygyny (group size was not considered) on data from 104 societies has strongly confirmed the findings of the earlier study.

The thrust of the rest of Mealey and Young's remarks is that it is demographically impossible for any man in a group of less than 50 to enjoy more than 100 simultaneous conjugal unions. This point is well taken. Mealey and Young, however, take the argument steps further, and suggest that men in groups of 50-500 and 50020,000 cannot possibly have more than 10 or more than 100 such unions, respectively. This isn't necessarily so. In, for example, a society made up of as few as 55 individuals, given a generous assumption that three fifths of them are not yet marriageable (i.e, under 20 or 25 years old), and given a roughly equal adult sex ratio, 11 women of marriageable age should be available. It is, then, demographically possible for a man, even in a small society of 50 to 500 mem-

Revised April 18, 1984

Address reprint requests to: L. L. Betzig, Museum of Zoology, University of Michigan, Ann Arbor, MI 48109. hers (code 2 on the groun size variable) to have 11 to 100 wives (code 3 on the degree of polygyny variable). Making a similar assumption of expanding population in the other group size categories, a minimum of 100 and 4000 women of marriageable age should be available in groups of $500-20,000$ and over 20,000 . The effect of all of which is that the only associations which should have been excluded from this analysis on demographic grounds are those between a group size rank of 1 (less than 50) and a polygyny variable rank of 3 or 4 (11-100 and over 100 wives), and a group size rank of $2(50-500)$ and a polygyny variable rank of 4 . It is worth pointing out that even given Mealey and Young's overstringent assumptions, the relationships in question remain at or around the point of statistical significance in every case (see Betzig 1982, p. 212).

Mealey and Young also seem to suggest that correlations between polygyny and the remaining variables in the study, perquisites, hierarchy, and bias in conflict resolution (degree of "despotism "), should be subject to similar analytical constraints. This is inappropriate. Any degree of bias in conflict resolution is possible in societies of every degree of polygyny. The same is true of hierarchy, and of perquisites as I define them. The thrust of $m y$ argument has been that to the extent that their followers have no option but to yield to them, men will exploit positions of power to resolve conflicts in their own interest, and take proportionate reproductive rewards. If individuals have evolved to maximize genetic representation in descendant generations, despotism should coincide with differential reproduction. The evidence suggests that it does.

Last, my use of a fortuitously found stencil, with eight circles from one-eighth inch to eighteights of an inch in diameter, is responsible for the evidently oversized dots. That I had no in- 
tention to mislead should, I hope, be evident by my honest labeling of them. They now seem superfluous at any size, given strong correlations on a big enough sample.

In their abstract, Mealey and Young assert that the problems with the article in question are "common to studies utilizing preexisting data such as that of the HRAF." In defense of such studies: the vast majority which do make claims to generality use much larger samples than I did in this preliminary study; none have as yet used number of wives, rather than proportion of men married to more than one woman, as a measure of polygyny, and so risked making mistaken demographic assumptions; and no one else I know of doing cross cultural work is guilty of using "Gee whiz" dots. The reputation of cross cultural research, ever since Tylor, seems to have suffered maligning enough. It is extremely encouraging that sophisticated statisticians, such as White, Burton, and Dow (e.g., 1981) are coming up with usable solutions to problems such as Galton's, and making sound tests of general theoretical propositions on general (worldwide) data sets a possibility. The ethnographic record is, after all, "for the time being, all that is available to many of us." With the accelerating spread of Western culture which prompted the study of "anthropology" initially, it is soon all that will be.

Thanks to Mealey and Young for their comments.

\section{REFERENCES}

Betzig, L.L. Despotism and differential reproduction: a cross cultural correlation of conflict asymmetry, hierarchy, and degree of polygyny. Ethology and Sociobiology, 3: 209-221. (1982).

- Despotism and Differential Reproduction. Ph.D. Dissertation, Northwestern University (1983).

- Despotism and Differential Reproduction: $A$ Darwinian View of History. Hawthorne. New York: Aldine (in press).

White, D.R., Burton, M., and Dow., M Sexual division of labor in African agriculture. American Anthropologist, 83: 824-849 (1981). 